九州大学学術情報リポジトリ

Kyushu University Institutional Repository

腹部大動脈瘤に対するステントグラフト内挿術後の
血小板数の推移とタイプ II エンドリークの関係

井上，健太郎

ht tp://hdl. hand le. net/2324/4110404

出版情報: Kyushu University，2020，博士（医学），課程博士 バージョン：

権利関係 : 


\title{
Platelets reflect the fate of type II endoleak after endovascular aneurysm repair
}

\author{
Kentaro Inoue, MD, ${ }^{a, b}$ Tadashi Furuyama, MD, PhD, ${ }^{a}$ Shun Kurose, MD, ${ }^{a}$ Shinichiro Yoshino, MD, ${ }^{a}$ \\ Ken Nakayama, MD, ${ }^{a}$ Sho Yamashita, MD, ${ }^{a}$ Koichi Morisaki, MD, PhD, ${ }^{a}$ Masazumi Kume, MD, PhD, \\ Takuya Matsumoto, MD, PhD, ${ }^{c}$ and Masaki Mori, MD, PhD, ${ }^{a}$ Fukuoka, Beppu, and Chiba, Japan
}

\begin{abstract}
Objective: The management of type II endoleak (T2E) remains controversial because of the heterogeneous outcome. For blood-based screening to detect malignant T2E, we focused on platelets after endovascular aneurysm repair (EVAR) and compared them with the prognosis of T2Es.

Methods: From 2007 to 2015, there were 249 patients treated with EVAR for abdominal aortic aneurysm who were evaluated retrospectively. The mean follow-up period was $3.5 \pm 0.2$ years. T2Es that had aneurysm sac enlargement or converted to type I or type III endoleak were defined as malignant; the other T2Es were considered benign. Cases without any complications, including T2E, were defined as completed. We compared the platelet count on postoperative days (PODs) 1 to 7 with preoperative baseline values among the three groups. Sequentially, we calculated the cutoff of the platelet ratio on POD 7 to the baseline value in relation to malignant T2E using receiver operating characteristic analysis, and the cutoff ratio was $113 \%$ (sensitivity, $79 \%$; specificity, $58 \%$ ). We then reclassified T2E patients into T2E-high platelet (T2E-HP; $\geq 113 \%$ ) or T2E-low platelet (T2E-LP; <113\%) groups. The influence of platelets on T2E was evaluated with reintervention rate and cumulative aneurysm sac enlargement rate using the Kaplan-Meier method.
\end{abstract}

Results: T2Es were found in 70 patients (28\%), and 179 patients were assigned to the completed group. Malignant and benign T2Es were found in 33 and 37 patients, respectively. No difference was found in the preoperative baseline values. On POD 7, the platelet count in the malignant T2E group was significantly lower than that in the completed and benign T2E groups $\left(168 \times 10^{3} / \mu \mathrm{L}\right.$ vs $207 \times 10^{3} / \mu \mathrm{L}$ and $\left.201 \times 10^{3} / \mu \mathrm{L} ; \mathrm{P}=.0124\right)$. Then, 27 and 43 patients were assigned to the T2E-HP and T2E-LP groups, respectively. The reintervention-free survival rate in the T2E-LP group was lower than that in the completed group (at 3 years, $66.4 \% \pm 8.0 \%$ vs $71.9 \% \pm 4.0 \%$; $P=.0031$ ). Among T2E patients, the cumulative aneurysm sac enlargement rates in the T2E-LP group were significantly higher than those in the T2E-HP group (at 3 years, $34.6 \% \pm 8.2 \%$ vs $20.6 \% \pm 8.2 \% ; P=.0105)$. Univariate Cox proportional hazards analysis for the cumulative aneurysm sac enlargement rates among T2E patients showed that sex, dual antiplatelet therapy, and lower platelet ratio $(<113 \%)$ were significant predictors; multivariate analysis showed that T2E-LP was the only significant predictor (hazard ratio, 2.60; $P=.0355$ ).

Conclusions: The platelet count of patients with malignant T2Es on POD 7 was definitively lower than that of patients with completed EVAR or with benign T2Es. The lower platelet count on POD 7 could be a risk factor for aneurysm sac enlargement among patients with T2Es. (J Vasc Surg 2019; :1-8.)

Keywords: Abdominal aortic aneurysm; Endovascular aneurysm repair; Endoleak; Platelet; Aneurysm sac enlargement

In the last quarter of the 20th century, endovascular aneurysm repair (EVAR) of abdominal aortic aneurysm (AAA) became widespread; today, more than half of all AAA cases employ EVAR as the treatment procedure. ${ }^{1,2}$ At the same time, vascular surgeons have encountered

\footnotetext{
From the Department of Surgery and Science, Graduate School of Medical Sciences, Kyushu University, Fukuoka ; the Department of Vascular Surgery. Beppu Medical Center, Beppu ${ }^{\text {b }}$; and the Department of Vascular Surgery, International University of Health and Welfare, Chiba. ${ }^{c}$

Author conflict of interest: none.

Additional material for this article may be found online at www.jvascsurg.org. Correspondence: Tadashi Furuyama, MD, PhD, Department of Surgery and Science, Graduate School of Medical Sciences, Kyushu University, 3-1-1, Maidashi, Higashi-ku, Fukuoka 812-8582, Japan (e-mail: cdq43210@par.odn.ne.jp). The editors and reviewers of this article have no relevant financial relationships to disclose per the JVS policy that requires reviewers to decline review of any manuscript for which they may have a conflict of interest. 0741-5214

Copyright $(1) 2019$ by the Society for Vascular Surgery. Published by Elsevier Inc https://doi.org/10.1016/j.jvs.2019.09.062
}

an endovascular-specific problem, the so-called endoleak, that reduces the curability of EVAR.

Type I and type III endoleaks can be regarded as clinical failures and definitive indications for reintervention. However, the management of type II endoleaks (T2Es) is still controversial. From $20 \%$ to $40 \%$ of T2Es can stop the flow and be resolved spontaneously within 1 to 2 years, ${ }^{3-5}$ but the other persistent T2Es can cause aneurysm sac enlargement and require reintervention, the occurrence of which has been found to be up to $55 \%$ in 3 years. This heterogeneity of T2Es causes a dilemma for vascular surgeons attempting to make a decision about the indication for and timing of reintervention. One general indication for reintervention for T2Es is aneurysm sac enlargement during observation ${ }^{6}$; however, the diagnosis of sac enlargement requires a period of observation of more than half a year as well as imaging examinations, such as computed tomography (CT) and ultrasound. 7,8 Furthermore, diagnosis by only CT imaging can lead to the misclassification of endoleaks. ${ }^{9}$ Hence, even today, a 
completely successful EVAR with T2Es cannot be defined in the early postoperative period, and another marker for follow-up after EVAR is beneficial to detect primary "malignant" T2Es, which cause aneurysm sac enlargement.

In this study, to find a new predictor for potentially unsuccessful EVAR, we focused on another fundamental aspect of the etiology of AAA - impairment of blood coagulation. ${ }^{10}$ AAA is known to activate the state of blood coagulation and fibrinolysis in patients, ${ }^{10}$ which sometimes causes disseminated intravascular coagulation." Yamazumi et al $^{10}$ suggested that this impaired blood coagulation activity could be improved using open repair. Platelet count especially shows dynamic changes during AAA treatment. The platelet count of patients with AAA decreases to $<200 \times 10^{3} / \mu \mathrm{L}$, which is lower than that in healthy controls, and open repair can bring about recovery of the count to $>210 \times 10^{3} / \mu \mathrm{L}^{.10}$ Furthermore, notably, only the platelet count returned to its normal level after open repair, whereas levels of anticoagulant markers, such as thrombin-antithrombin III complex, D-dimer, and fibrinogen and fibrin degradation products, remained significantly high even 3 months after surgery. For EVAR, only an immediate decrease in platelet count just after treatment has been reported, ${ }^{12,13}$ but how the transition of platelets affects the prognosis of AAA has not been revealed. Therefore, in this study, we focused on the changes in platelets in the perioperative period of EVAR and assessed the relation between platelets and T2Es.

\section{METHODS}

This was a retrospective study in a single institution. All analyzed data were collected as part of routine diagnosis and treatment. The study protocol was approved by the hospital's institutional ethics committee and conducted in accordance with the Declaration of Helsinki. Informed consent was obtained before treatment.

Patients. Patients who underwent elective EVAR for nonruptured AAA from December 2007 to December 2015 were evaluated retrospectively. Our exclusion criteria were as follows: simultaneous thoracic EVAR, lack of follow-up data, and primary type I endoleak. There were 249 patients registered. The baseline characteristics of the patients, including age, sex, smoking history, comorbidities, and medication, were collected.

Follow-up and data registration. For imaging followup, patients routinely underwent a contrast-enhanced biphasic CT evaluation during the first 7 postoperative days (PODs). CT scans were then performed at 1 month, 3 months, 6 months, 1 year, and half a year or 1 year thereafter during follow-up. Primary T2Es were diagnosed with postoperative CT within 1 month.

Patients were followed up for mortality and aneurysm sac growth over time. An enlargement of $5 \mathrm{~mm}$ above the preoperative axial diameter of the aneurysm was

\section{ARTICLE HIGHLIGHTS}

Type of Research: Single-center, retrospective cohort study

Key Findings: In endovascular aneurysm repair (EVAR) of 249 patients, platelet count after EVAR in those with malignant type II endoleak (T2E), which causes aneurysm sac enlargement or converts to type I or type III endoleak, is definitively lower than that of patients without malignant T2Es.

Take Home Message: The lower platelet count after EVAR can be a risk factor for aneurysm sac enlargement among patients with T2Es.

defined as sac enlargement. T2Es that had aneurysm sac enlargement or converted to type I or type III endoleak were defined as malignant T2Es. ${ }^{14,15}$ Conversely, cases without any endoleaks, reintervention, or sac enlargement during observation were defined as completed cases. The mean follow-up period was $3.5 \pm$ 0.2 (95\% confidence interval, 3.2-3.8) years.

All patients' preoperative data were collected within 1 month before treatment. The postoperative platelet count according to the complete blood count on POD 1 and POD 7 was also registered.

Aneurysm characteristics and treatment procedures. The aneurysm was evaluated for shape, size, and presence of concomitant iliac artery aneurysms. We classified the model and material of stent grafts. The stent grafts used were Zenith Flex (Cook Medical, Bloomington, Ind), GORE Excluder (W. L. Gore \& Associates, Flagstaff, Ariz), Powerlink (Endologix, Irvine, Calif), Endurant II (Medtronic, Santa Rosa, Calif), and Aorfix (Lombard Medical Technologies, Oxfordshire, United Kingdom). All EVAR treatments were performed under general anesthesia with surgical cutdown femoral artery access.

Outcomes. The reintervention-free survival rate was calculated in all patients. The cumulative aneurysm sac enlargement rate in patients with T2E was evaluated for the period to sac growth of $>5 \mathrm{~mm}$, regardless of whether additional treatments were performed for AAA.

Statistical analysis. Statistical analysis was performed with JMP version 13 (SAS Institute, Cary, NC). The categorical variables were compared using Fisher exact test. The continuous variables are shown as mean \pm standard error and range. For multiple comparisons of continuous variables, one-way analysis of variance (ANOVA) accompanied by Student $t$-test was used as appropriate. $P$ values of $t$-test were referred to in figures, tables, or manuscripts as significant differences. The Kaplan-Meier method was used to estimate cumulative aneurysm sac enlargement rates and overall survival rates among patients with T2E. The resulting curves of the Kaplan-Meier 


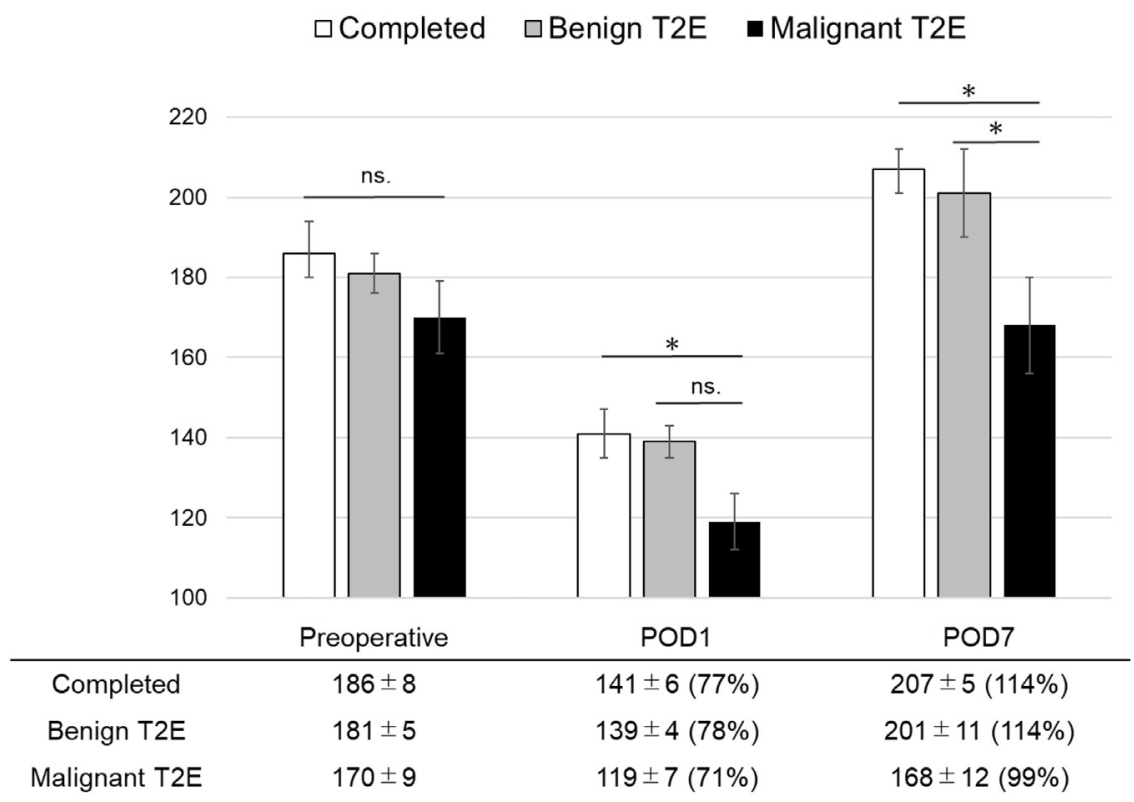

Fig 1. Changes in platelet count among the completed, benign type II endoleak (T2E), and malignant T2E groups. The percentage of patients is given in parentheses. Continuous data are shown as mean \pm standard error. $n s$, Not significant; $P O D$, postoperative day.

method were compared using the log-rank test. A Cox proportional hazards model was used for univariate and multivariate analyses of the risks of cumulative aneurysm sac enlargement rates. $P$ values $<.05$ were considered statistically significant.

\section{RESULTS}

Lower platelet counts on POD 7 in patients with malignant T2E. T2Es were found in 70 of 249 patients (28\%), and 179 patients were assigned to the completed group. In 70 patients with T2E, 7 cases and 1 case converted to type I and type III endoleaks, respectively. An additional 26 treatments were performed: embolization with $n$-butyl-2-cyanoacrylate or coil, 16 cases; additional EVAR, 7 cases; and open conversion, 3 cases. Seven cases with aneurysm sac enlargement were only observed. Consequently, 33 cases were diagnosed as malignant T2Es. Among the rest of the T2E cases (37 benign cases), spontaneous disappearance was confirmed in 16 cases at 6 months (43\%).

First, we compared platelet counts within 1 week after EVAR among completed, benign T2E, and malignant T2E groups (Fig 1). There was no significant difference in preoperative platelet counts among the groups $(P=.3541)$. However, the malignant T2E group showed a significantly lower platelet count on POD 1 ( $t$-test, $P=$ .0149; ANOVA, $P=.0507$ ) and POD 7 ( $t$-test, $P=.0031$; ANOVA, $P=.00124)$ compared with the completed group. On POD 7, the platelet count in the benign T2E group was also significantly higher than that in the malignant T2E group ( $t$-test, $P=.0475$ ).
Patient, AAA, and treatment characteristics in the groups with high or low platelet levels. Next, to clarify whether this difference of platelet count can be practically applied to detection of malignant T2E, we decided to reclassify T2E patients into two groups according to the postoperative platelet state. To modify the preoperative individual difference, the ratios of platelet count on POD 7 to the preoperative baseline values were calculated (Fig 1, percentage in parentheses). Notably, the ratios of the completed and benign T2E groups showed the same value (114\%). Sequentially, we calculated the optimal cutoff value of the platelet ratio in relation to malignant T2E using the receiver operating characteristic analysis; the optimal cutoff ratio was $113 \%$ (area under the curve, 0.67; sensitivity, 78.8\%; specificity, 58.0\%). Then, we divided the T2E patients into the high platelet group (T2E-HP; $2113 \%$ ) and the low platelet group (T2ELP; $<113 \%)$.

The backgrounds of the patients of these T2E groups and the completed group are shown in Table I. Of 70 patients, 43 (61\%) were assigned to the T2E-LP group. In comparing the characteristics of the patients, only sex showed a significant difference between T2E-LP and T2E-HP groups ( $P=.0048$; ANOVA, $P=.0061)$ There was no difference in medications. Regarding laboratory data, the white blood cell counts in the T2E-LP group were significantly lower than those in the completed group ( $P=.0137$; ANOVA, $P=.0144)$. Prothrombin time \% in the T2E-HP group was higher than that in the completed group $(P=.0114$; ANOVA, $P=$ .0172). 
Table I. Patients' background and laboratory data among the groups

\begin{tabular}{|c|c|c|c|c|c|}
\hline Variables & Total $(\mathrm{N}=249)$ & Completed $(n=179)$ & T2E-HP $(n=27)$ & T2E-LP $(n=43)$ & $P$ value \\
\hline Age, years & $75.3 \pm 0.5(74.2-76.3)$ & $75.3 \pm 0.6(69.8-76.5)$ & $72.9 \pm 1.6(69.8-76.0)$ & $76.1 \pm 0.7(74.7-77.6)$ & .1449 \\
\hline Sex, male & $216(87)$ & $157(88)$ & $27(100)$ & $32(74)$ & .0061 \\
\hline Hypertension & $201(81)$ & $145(81)$ & $21(78)$ & $35(81)$ & .9020 \\
\hline Diabetes mellitus & $62(25)$ & $43(24)$ & $7(26)$ & $12(28)$ & .8648 \\
\hline Dyslipidemia & $89(36)$ & $68(38)$ & $10(37)$ & $11(26)$ & .3205 \\
\hline Cerebrovascular disease & $69(28)$ & $51(28)$ & $6(22)$ & $12(28)$ & .8498 \\
\hline Atrial fibrillation & $22(9)$ & $18(10)$ & $2(7)$ & $2(5)$ & .6266 \\
\hline End-stage renal disease & $6(2)$ & $5(3)$ & $1(4)$ & $\mathrm{O}(0)$ & .5113 \\
\hline \multicolumn{6}{|l|}{ Medication } \\
\hline Statin & $127(51)$ & $88(49)$ & $17(63)$ & $22(51)$ & .4184 \\
\hline DAPT & $29(12)$ & $15(8)$ & 7 (26) & $7(16)$ & \\
\hline Anticoagulant therapy & $19(8)$ & $18(10)$ & $\mathrm{O}(0)$ & $1(2)$ & .0841 \\
\hline \multicolumn{6}{|l|}{ Laboratory data } \\
\hline White blood cells, $10^{3} / \mu \mathrm{L}$ & $6.6 \pm 0.1(6.1-6.7)$ & $6.6 \pm 0.2(6.3-7.0)$ & $5.8 \pm 0.4(5.1-6.5)$ & $5.7 \pm 0.3(5.1-6.3)$ & .0144 \\
\hline Hemoglobin, g/dL & $12.7 \pm 0.1(12.5-12.9)$ & $12.7 \pm 0.1(12.4-13.0)$ & $12.8 \pm 0.4(12.1-13.5)$ & $12.6 \pm 0.3(12.0-13.1)$ & .8526 \\
\hline Platelet, $\times 10^{3} / \mu \mathrm{L}$ & $183 \pm 4(175-190)$ & $186 \pm 4(177-194)$ & $165 \pm 11(143-187)$ & $183 \pm 9(165-200)$ & .2277 \\
\hline Creatinine, $\mathrm{mg} / \mathrm{dL}$ & $1.18 \pm 0.06$ (1.07-1.29) & $1.22 \pm 0.07(1.08-1.35)$ & $1.27 \pm 0.17(0.94-1.61)$ & $0.98 \pm 0.14(0.72-1.25)$ & .2650 \\
\hline $\begin{array}{l}\text { C-reactive } \\
\text { protein, } \mathrm{mg} / \mathrm{dL}\end{array}$ & $0.63 \pm 0.10(0.43-0.84)$ & $0.75 \pm 0.12(0.51-0.98)$ & $\begin{array}{c}0.14 \pm 0.37 \\
(-0.52 \text { to } 0.80)\end{array}$ & $\begin{array}{l}0.43 \pm 0.25 \\
(-0.06 \text { to } 0.91)\end{array}$ & .1554 \\
\hline PT, \% & $92 \pm 1(90-95)$ & $90 \pm 1(87-93)$ & $100 \pm 4(93-108)$ & $96 \pm 3(90-101)$ & .0172 \\
\hline
\end{tabular}

The AAA and treatment characteristics are summarized in Table II. No characteristics of AAA differed among the three groups.

In terms of treatment, expanded polytetrafluoroethylenebased stent grafts were more frequently used in both T2E-HP and T2E-LP groups than in the completed group ( $P=.0054$ and $P=.0229$, respectively). For landing zones, the aortic neck length in the completed group was significantly less than that in the other two groups (vs T2E-HP, $P=.0113$; vs T2E-LP; $P=.0226)$.

Reintervention-free survival and cumulative aneurysm sac enlargement rates. The reintervention-free survival rates in the completed and T2E groups are described in Fig 2. No significant difference was found between the completed and T2E-HP groups (the 1-year rates were $88.3 \% \pm 2.5 \%$ vs $100 \% \pm 0.0 \%$, the 2 -year rates were $77.1 \% \pm 3.5 \%$ vs $96.2 \% \pm 3.8 \%$, and the 3 -year rates were $71.9 \% \pm 4.0 \%$ vs $78.7 \% \pm 8.5 \%$, respectively; $P=.9290$ ). In contrast, the reintervention-free survival rate of the T2E-LP group was significantly lower than that of the completed group after 2 years (the 1-, 2-, and 3-year rates were $92.4 \% \pm 4.2 \%, 78.6 \% \pm 6.7 \%$, and $66.4 \% \pm$ $8.0 \%$, respectively; $P=.0031$ ).

Fig 3 shows the cumulative aneurysm sac enlargement rates in patients with T2E. The rate in the T2E-LP group was significantly higher than that in the T2E-HP group (the 1-year rates were $7.6 \% \pm 4.2 \%$ vs $0.0 \% \pm 0.0 \%$, the 2 -year rates were $19.0 \% \pm 6.5 \%$ vs $3.9 \% \pm 3.7 \%$, and the 3 -year rates were $34.6 \% \pm 8.2 \%$ vs $20.6 \% \pm 8.2 \%$, respectively; $P=.0105)$, and the rates in the T2E-LP group reached up to $48.6 \% \pm 8.9 \%$ at 3.5 years.

Table III shows the results of the univariate and multivariate Cox proportional hazards analyses for the cumulative aneurysm sac enlargement rates in $\mathrm{T} 2 \mathrm{E}$ patients. Univariate analysis showed that sex, dual antiplatelet therapy (DAPT), and lower platelet ratio on POD $7(<113 \%)$ were significant predictors. There were no significant variables in comorbidities, anatomic conditions of AAA, and treatment (Supplementary Table, online only). Multivariate analysis showed that T2E-LP was the only significant predictor (hazard ratio, 2.60; $P=$.0355). 
Table II. Characteristics of aneurysm and treatment among the groups

\begin{tabular}{|c|c|c|c|c|}
\hline Variables & Completed $(n=179)$ & T2E-HP $(n=27)$ & T2E-LP $(n=43)$ & $P$ value \\
\hline \multicolumn{5}{|l|}{ Aneurysm } \\
\hline Size, $\mathrm{mm}$ & $5.1 \pm 0.6(4.9-5.2)$ & $5.3 \pm 1.6(5.0-5.7)$ & $5.0 \pm 1.3(4.8-5.3)$ & .2636 \\
\hline Shape, saccular & $12(7)$ & $3(11)$ & $5(12)$ & .4347 \\
\hline Concomitant iliac artery aneurysm & $26(15)$ & $7(26)$ & $11(26)$ & .1101 \\
\hline \multicolumn{5}{|l|}{ Stent graft model } \\
\hline Zenith Flex & $56(31)$ & $5(19)$ & $7(16)$ & .3008 \\
\hline Powerlink & $15(8)$ & $\mathrm{O}(0)$ & $5(11)$ & \\
\hline Excluder & $46(26)$ & $17(63)$ & $18(42)$ & \\
\hline Endurant II & $58(32)$ & $3(11)$ & $12(28)$ & \\
\hline Aorfix & $4(2)$ & $2(7)$ & $1(3)$ & \\
\hline Stent graft material (ePTFE) & $61(34)$ & $17(63)$ & $23(53)$ & .0027 \\
\hline \multicolumn{5}{|l|}{ Proximal landing } \\
\hline Aortic neck length, mm & $26.3 \pm 1.0(24.3-28.2)$ & $33.3 \pm 2.6(28.3-38.3)$ & $31.5 \pm 2.0(27.5-35.5)$ & .0068 \\
\hline Aortic neck diameter, mm & $21.8 \pm 0.3(21.2-22.3)$ & $21.4 \pm 0.7(20.0-22.8)$ & $21.4 \pm 0.6(20.3-22.5)$ & .7872 \\
\hline Aortic neck angle $<60$ degrees & $177(86)$ & $68(86)$ & $109(87)$ & .8299 \\
\hline \multicolumn{5}{|l|}{ Distal landing } \\
\hline Right limb landing length, mm & $33.1 \pm 1.0(31.2-35.0)$ & $31.7 \pm 2.5(26.9-36.6)$ & $34.0 \pm 2.0(30.1-37.8)$ & .7795 \\
\hline Right limb landing diameter, $\mathrm{mm}$ & $13.8 \pm 0.3(13.2-14.5)$ & $12.4 \pm 0.8(10.7-14.0)$ & $13.4 \pm 0.7(12.1-14.7)$ & .2572 \\
\hline Left limb landing length, $\mathrm{mm}$ & $37.5 \pm 1.2(35.1-39.9)$ & $38.9 \pm 3.1(32.6-45.1)$ & $37.0 \pm 2.5(32.1-41.9)$ & .8923 \\
\hline Left limb landing diameter, mm & $13.5 \pm 0.3(12.9-14.1)$ & $13.0 \pm 0.8(11.5-14.5)$ & $13.8 \pm 0.6(12.6-15.1)$ & .7025 \\
\hline Operation time, minutes & $309 \pm 28(255-364)$ & $243 \pm 72(100-386)$ & $360 \pm 56(249-470)$ & .4470 \\
\hline Blood loss, $\mathrm{mL}$ & $303 \pm 24(255-351)$ & $262 \pm 43(177-348)$ & $337 \pm 34(270-405)$ & .4442 \\
\hline Blood transfusion & $28(16)$ & $2(7)$ & $11(26)$ & .1293 \\
\hline \multicolumn{5}{|l|}{ Artery of T2Es } \\
\hline IMA & & $9(33)$ & $6(14)$ & \\
\hline LA & & $15(11)$ & $31(72)$ & .1778 \\
\hline Both IMA and LA & & $3(56)$ & $6(14)$ & \\
\hline $\begin{array}{l}\text { ePTFE, Expanded polytetrafluoroethylene; } \\
\text { endoleak. } \\
\text { Categorical variables are presented as num }\end{array}$ & $\begin{array}{l}\text { igh platelet ratio; IMA, in } \\
\%) \text {. Continuous variables }\end{array}$ & mesentery artery; $L A$, lum & $\begin{array}{l}\text { artery: } L P \text {, low platelet } r \\
\text { error (range). }\end{array}$ & E, type II \\
\hline
\end{tabular}

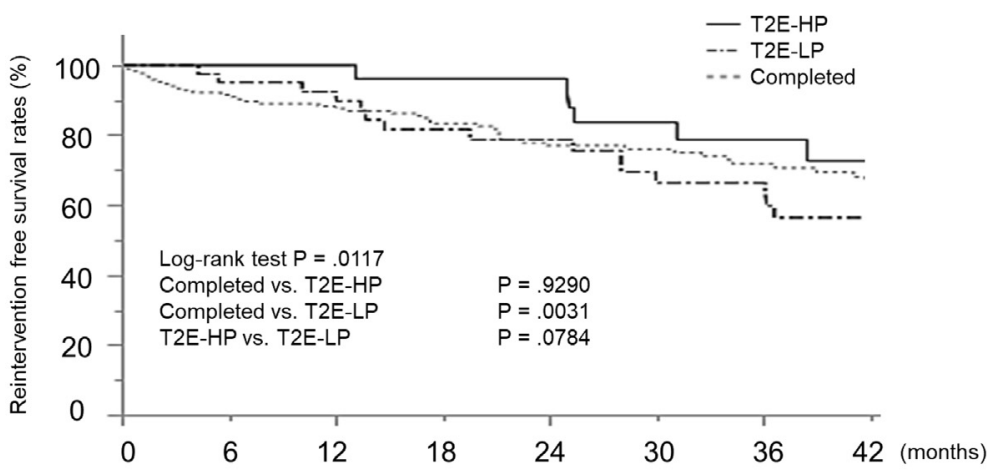

Number at risk

$\begin{array}{ccccccccc}\text { Completed } & 179 & 145 & 133 & 112 & 96 & 77 & 65 & 50 \\ \text { T2E-HP } & 27 & 27 & 27 & 26 & 25 & 19 & 15 & 10 \\ \text { T2E-LP } & 43 & 39 & 36 & 31 & 27 & 22 & 21 & 17\end{array}$

Fig 2. Reintervention-free survival rates among the completed, type II endoleak-high platelet ratio (T2E-HP), and type II endoleak-low platelet ratio $(T 2 E-L P)$ groups. 


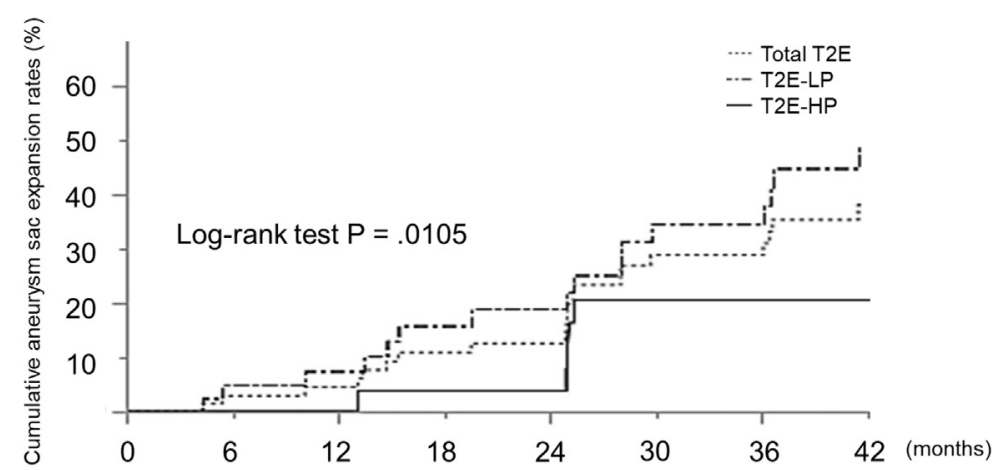

Number at risk

$\begin{array}{rllllllll}\text { Total T2E } & 70 & 66 & 63 & 57 & 51 & 40 & 35 & 25 \\ \text { T2E-LP } & 43 & 39 & 37 & 31 & 27 & 24 & 21 & 16 \\ \text { T2E-HP } & 27 & 27 & 27 & 26 & 25 & 18 & 15 & 10\end{array}$

Fig 3. Cumulative aneurysm sac expansion rates among the completed, type II endoleak-high platelet ratio ( $T 2 E$ $H P)$, and type II endoleak-low platelet ratio (T2E-LP) groups. T2E, Type II endoleak.

Table III. Cox proportional analysis of cumulative aneurysm sac enlargement rates among patients with type II endoleak (T2E)

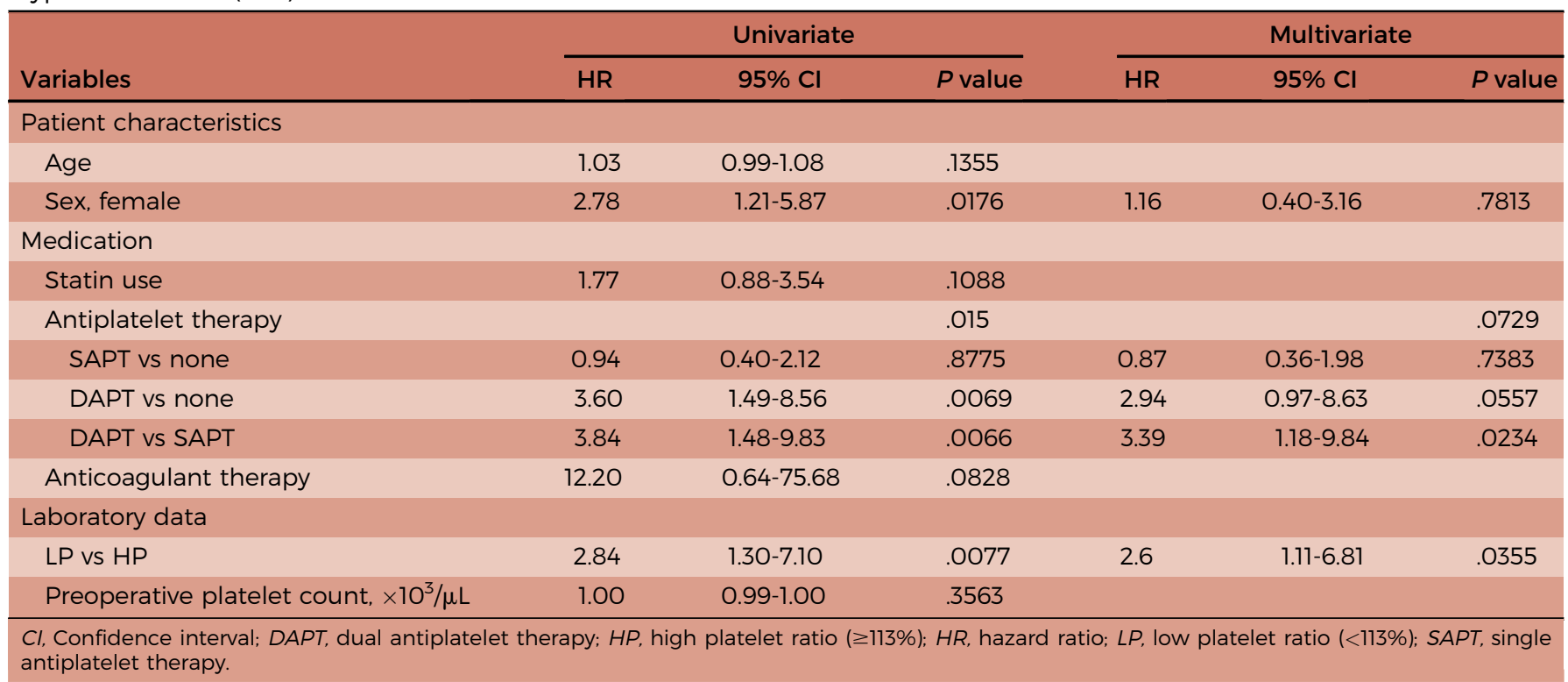

\section{DISCUSSION}

In this study, 33 of 70 (47\%) cases with T2Es were malignant, which required reintervention or showed aneurysm sac enlargement, and the cumulative aneurysm sac enlargement rate at 3 years among patients with T2Es in this study was $28.9 \%$ (Fig 3, dotted line). This prevalence consisted of the previously reported rates: $20 \%$ to $55 \%$ within 3 years. ${ }^{3,16,17}$ To predict this unfavorable fate of T2Es, previous reports mainly focused on anatomic and morphologic assessment; the well-known risks of persistent/malignant T2Es were the opening of the inferior mesentery artery and lumbar arteries, ${ }^{18}$ the number of lumbar arteries (four or more), ${ }^{16}$ and the diameter of the inferior mesentery artery $(\geq 2.6 \mathrm{~mm})$ and lumbar artery $(\geq 1.9 \mathrm{~mm}){ }^{19}$ Recent studies attempted to evaluate blood flow velocity directly with imaging-based procedures, such as four-dimensional flow-sensitive magnetic resonance imaging $^{5}$ and ultrasound. ${ }^{20,21}$ The peak systolic velocity of T2Es, however, was too tiny to detect completely in ordinal clinical practice; the peak systolic velocity even in high-flow T2E cases reached $>30 \mathrm{~cm} / \mathrm{s}^{27}$ which was similar to that of tibial arteries of patients with peripheral artery disease. ${ }^{22}$ In addition, even the type of endoleak can be misclassified on CT, such as type I or type III endoleak as T2Es, and angiography is 
sometimes required for correct diagnosis. ${ }^{9}$ These findings suggest that follow-up only with imaging-based examinations has a detection threshold of malignant T2Es.

In this circumstance, we attempted to find a surrogate marker for predicting malignant T2Es with respect to thrombology. EVAR is known to affect platelet count and to reduce the platelet count to $150 \times 10^{3} / \mu \mathrm{L}$ on POD 1. ${ }^{12,13}$ In concordance with this, platelet count reduction to within the range of 119 to $141 \times 10^{3} / \mu \mathrm{L}$ on POD 1 was shown with or without T2Es. In addition, the increase of platelet count on POD 7 was significantly attenuated by malignant T2Es (Fig 1). Furthermore, the postoperative platelet count of completed EVAR reached $207 \times 10^{3} / \mu \mathrm{L}$, which was almost equal to that of open repair $\left(210 \times 10^{3} / \mu \mathrm{L}\right)^{10}{ }^{10}$ These results suggested that 7 days is enough to restore the impaired platelet activity due to AAA and that platelets can be a marker of "true exclusion" after EVAR.

Cumulative reintervention-free survival rates and aneurysm sac enlargement rates also suggested that lower platelet count after EVAR is a negative predictor (T2E-LP in Figs 2 and 3). Cox proportional hazards analysis confirmed that T2E-LP is an independent predictor of aneurysm sac enlargement as well as female sex and DAPT among T2E patients, and T2E-LP was found to be a significant risk factor using multivariate analysis (Table III). Female sex was reported as nearly significant higher risk for development of T2Es. ${ }^{18}$ DAPT was also reported as a risk factor for aneurysm sac growth. ${ }^{23}$ Hence, our result did not contradict these previous findings. For antiplatelet therapy, interestingly, single antiplatelet therapy with aspirin has not been regarded as a risk factor for aneurysm sac enlargement. ${ }^{23}$ Furthermore, Owens et $\mathrm{al}^{24}$ suggested that the administration of aspirin or $\mathrm{P}_{2} \mathrm{Y}_{12}$ inhibitors alone was associated with reduced death among patients with AAA owing to the reduction of macrophage recruitment, resulting in decreased active matrix metalloproteinases 2 and 9. These facts were confusing because they posed a new question to vascular surgeons: Should platelets be active or not to repress AAA development? To summarize the results in this study. AAA causes an abnormal activity of platelets by reducing the count (which can be recovered by complete treatment), and modification by a platelet inhibitor partially improves the impaired activity. Further studies are required to reveal how active platelets behave in AAA and after treatment.

This study has several limitations. This was a retrospective single-center study with a small sample size. Platelet count is an indirect platelet activation marker and can be affected not only by AAAs but also by other systemic conditions. We were unable to obtain sufficient perioperative data of other hemostatic markers and to compare them with the platelet count.
To date, blood test-based screening for endoleak has not been defined. However, it can be an attractive follow-up method because of its reproducibility and ease. Furthermore, it can contribute to cost reduction with respect to time and personnel. Davies et $\mathrm{a}^{25}$ have suggested that the platelet, fibrinogen, and plasminogen levels as well as prothrombin activity of patients undergoing EVAR significantly decrease within the first 10 days after the procedure and that all biomarkers return to their preoperative levels, except for fibrinogen. However, these findings focused only on limited perioperative periods, and how they influenced the clinical outcomes of EVAR, including the occurrence of endoleak, and reintervention was not required. In addition, the sample size of each study in their review was small. ${ }^{26-28}$ Therefore, before changes in blood components after EVAR can be used in clinical practice, further prospective studies must be conducted to assess the relationship between the dynamics of coagulation and platelet activity and long-term outcomes after EVAR, including endoleak occurrence and aneurysm sac enlargement.

\section{CONCLUSIONS}

After EVAR, platelet counts in patients with malignant T2Es on POD 7 were significantly lower than those in patients with completed EVAR or with benign T2Es. The lower platelet ratio on POD 7 compared with the postoperative value could have been a risk factor for aneurysm sac enlargement among cases with T2Es. Further studies are required to reveal how platelet activity and coagulation change after EVAR, and this attempt can be expected to contribute to establishment of a completely new approach for follow-up without missing malignant T2Es.

\section{AUTHOR CONTRIBUTIONS}

Conception and design: $\mathrm{KI}$

Analysis and interpretation: KI, TF, KM, MK, TM, MM

Data collection: SK, ShiY, KN, ShoY, KM

Writing the article: KI

Critical revision of the article: TF, SK, ShiY, KN, ShoY, KM, MK, TM, MM

Final approval of the article: KI, TF, SK, ShiY, KN, ShoY, KM, MK, TM, MM

Statistical analysis: Not applicable

Obtained funding: Not applicable

Overall responsibility: TF

\section{REFERENCES}

1. Lilja F, Mani K, Wanhainen A. Editor's choice-trend-break in abdominal aortic aneurysm repair with decreasing surgical workload. Eur J Vasc Endovasc Surg 2017;53:811-9.

2. Hurks R, Ultee KH, Buck DB, DaSilva GS, Soden PA, van Herwaarden JA, et al. The impact of endovascular repair on specialties performing abdominal aortic aneurysm repair J Vasc Surg 2015;62:562-8.e3.

3. van Marrewijk CJ, Fransen C, Laheij RJ, Harris PL, Buth J. Is a type II endoleak after EVAR a harbinger of risk? Causes and 
outcome of open conversion and aneurysm rupture during follow-up. Eur J Vasc Endovasc Surg 2004;27:128-37.

4. Lo RC, Buck DB, Herrmann J, Hamdan AD, Wyers M, Patel VI, et al. Risk factors and consequences of persistent type II endoleaks. J Vasc Surg 2016;63:895-901.

5. Katahashi K, Sano M, Takehara Y, Inuzuka K, Sugiyama M, Alley MT, et al. Flow dynamics of type II endoleaks can determine sac expansion after endovascular aneurysm repair using four-dimensional flow-sensitive magnetic resonance imaging analysis. J Vasc Surg 2019;70:107-16.el.

6. Ultee $\mathrm{KH}$, Büttner $\mathrm{S}$, Huurman R, Bastos Gonçalves $\mathrm{F}$, Hoeks SE, Bramer WM, et al. Editor's choice-systematic review and meta-analysis of the outcome of treatment for type II endoleak following endovascular aneurysm repair. Eur J Vasc Endovasc Surg 2018;56:794-807.

7. Chaikof EL, Dalman RL, Eskandari MK, Jackson BM, Lee WA, Mansour MA, et al. The Society for Vascular Surgery practice guidelines on the care of patients with an abdominal aortic aneurysm. J Vasc Surg 2018;67:2-77.e2.

8. Wanhainen A, Verzini F, Van Herzeele I, Allaire E, Bown M, Cohnert T, et al. Editor's choice-European Society for Vascular Surgery (ESVS) 2019 clinical practice guidelines on the management of abdominal aorto-iliac artery aneurysms. Eur J Vasc Endovasc Surg 2019;57:8-93.

9. Funaki B, Birouti N, Zangan SM, Van Ha TG, Lorenz JM, Navuluri R, et al. Evaluation and treatment of suspected type II endoleaks in patients with enlarging abdominal aortic aneurysms. J Vasc Interv Radiol 2012;23:866-72.

10. Yamazumi K, Ojiro M, Okumura H, Aikou T. An activated state of blood coagulation and fibrinolysis in patients with abdominal aortic aneurysm. Am J Surg 1998;175:297-301.

11. Fisher DF Jr, Yawn DH, Crawford ES. Preoperative disseminated intravascular coagulation associated with aortic aneurysms: a prospective study of 76 cases. Arch Surg 1983;118: 1252-5.

12. Kakisis JD, Moulakakis KG, Antonopoulos CN, Mylonas SN, Giannakopoulos TC, Sfyroeras GS, et al. Volume of new-onset thrombus is associated with the development of postimplantation syndrome after endovascular aneurysm repair. J Vasc Surg 2014;60:1140-5.

13. Arnaoutoglou E, Kouvelos G, Papa N, Karamoutsios A, Bouris V, Vartholomatos G, et al. Platelet activation after endovascular repair of abdominal aortic aneurysm. Vascular 2016:24:287-94.

14. Avgerinos ED, Chaer RA, Makaroun MS. Type II endoleaks. J Vasc Surg 2014;60:1386-91.

15. Madigan MC, Singh MJ, Chaer RA, Al-Khoury GE, Makaroun MS. Occult type I or III endoleaks are a common cause of failure of type II endoleak treatment after endovascular aortic repair. J Vasc Surg 2019;69:432-9.

16. Seike Y, Matsuda H, Fukuda T, Inoue Y, Omura A, Uehara K, et al. The influence of 4 or more patent lumbar arteries on persistent type II endoleak and sac expansion after endovascular aneurysm repair. Ann Vasc Surg 2018;50:195-201.

17. Jouhannet C, Alsac JM, Julia P, Sapoval M, El Batti S, Di Primio $\mathrm{M}$, et al. Reinterventions for type 2 endoleaks with enlargement of the aneurismal sac after endovascular treatment of abdominal aortic aneurysms. Ann Vasc Surg 2014:28:192-200.

18. Lalys F, Durrmann V, Dumenil A, Goksu C, Cardon A, Clochard E, et al. Systematic review and meta-analysis of preoperative risk factors of type II endoleaks after endovascular aneurysm repair. Ann Vasc Surg 2017:41:284-93.

19. Otsu M, Ishizaka T, Watanabe M, Hori T, Kohno H, Ishida K, et al. Analysis of anatomical risk factors for persistent type ॥ endoleaks following endovascular abdominal aortic aneurysm repair using CT angiography. Surg Today 2016;46:48-55.

20. Tuleja A, Thalhammer C. Ultrasound flow velocity patterns in surveillance of type II endoleaks - the clue for the prediction of aneurysm rupture? Vasa 2018:47:430.

21. Monastiriotis S, Lau I, Loh S, Ferretti J, Tassiopoulos A, Labropoulos N. Evolution of type II endoleaks based on different ultrasound-identified patterns. J Vasc Surg 2018;67: 1074-81.

22. Crawford JD, Robbins NG, Harry LA, Wilson DG, McLafferty RB, Mitchell EL, et al. Characterization of tibial velocities by duplex ultrasound in severe peripheral arterial disease and controls. J Vasc Surg 2016;63:646-51.

23. Alvarez Marcos F, Llaneza Coto JM, Franco Meijide FJ, Zanabili Al-Sibbai AA, Vilarino Rico J, Alonso Perez M, et al. Effect of antiplatelet therapy on aneurysmal sac expansion associated with type II endoleaks after endovascular aneurysm repair. J Vasc Surg 2017;66:396-403.

24. Owens AP 3rd, Edwards TL, Antoniak S, Geddings JE, Jahangir E, Wei WQ, et al. Platelet inhibitors reduce rupture in a mouse model of established abdominal aortic aneurysm. Arterioscler Thromb Vasc Biol 2015;35:2032-41.

25. Davies RS, Abdelhamid M, Wall ML, Vohra RK, Bradbury AW, Adam DJ. Coagulation, fibrinolysis, and platelet activation in patients undergoing open and endovascular repair of abdominal aortic aneurysm. J Vasc Surg 2011;54:865-78.

26. Aho PS, Niemi T, Piilonen A, Lassila R, Renkonen R, Lepäntalo M. Interplay between coagulation and inflammation in open and endovascular abdominal aortic aneurysm repair-impact of intra-aneurysmal thrombus. Scand J Surg 2007;96:229-35.

27. Monaco M, Di Tommaso L, Stassano P, Smimmo R, De Amicis V, Pantaleo A, et al. Impact of blood coagulation and fibrinolytic system changes on early and mid term clinical outcome in patients undergoing stent endografting surgery. Interact Cardiovasc Thorac Surg 2006;5:724-8.

28. Serino F, Abeni D, Galvagni E, Sardella SG, Scuro A, Ferrari M, et al. Noninvasive diagnosis of incomplete endovascular aneurysm repair: D-dimer assay to detect type I endoleaks and nonshrinking aneurysms. J Endovasc Ther 2002;9:90-7.

Submitted Jun 17, 2019; accepted Sep 28, 2019.

Additional material for this article may be found online at www.jvascsurg.org. 
Journal of Vascular Surgery

Volume $\mathbf{a}$, Number

Supplementary Table (online only). Univariate Cox proportional analysis of cumulative aneurysm sac enlargement rates among type II endoleak (T2E) patients for other variables

\begin{tabular}{|c|c|c|c|}
\hline \multirow[b]{2}{*}{ Variables } & \multicolumn{3}{|c|}{ Univariate } \\
\hline & HR & $95 \% \mathrm{Cl}$ & $P$ value \\
\hline \multicolumn{4}{|l|}{ Comorbidities } \\
\hline Hypertension & 0.81 & $0.35-2.19$ & .6462 \\
\hline Diabetes mellitus & 1.29 & $0.56-2.70$ & .5279 \\
\hline Dyslipidemia & 1.43 & $0.65-2.94$ & .3617 \\
\hline Coronary artery disease & 1.78 & $0.87-3.53$ & .1154 \\
\hline Cerebrovascular disease & 0.51 & $0.20-1.15$ & 1092 \\
\hline Atrial fibrillation & 0.6 & $0.03-2.86$ & .5915 \\
\hline End-stage renal disease & 4.91 & $0.27-25.31$ & .2154 \\
\hline \multicolumn{4}{|l|}{ Laboratory data } \\
\hline C-reactive protein, $\mathrm{mg} / \mathrm{dL}$ & 1.36 & 0.97-1.70 & .0679 \\
\hline PT, \% & 0.99 & $0.95-1.02$ & .4557 \\
\hline APTT, seconds & 0.98 & $0.87-1.11$ & .7989 \\
\hline \multicolumn{4}{|l|}{ Aneurysm } \\
\hline Size, $\mathrm{mm}$ & 1.00 & $0.96-1.04$ & .9751 \\
\hline Shape, saccular & 0.46 & $0.07-1.53$ & .2338 \\
\hline Concomitant iliac aneurysm & 1.58 & $0.71-3.25$ & .2455 \\
\hline Aortic neck length, mm & 0.98 & $0.95-1.00$ & .1219 \\
\hline Aortic neck diameter, $\mathrm{mm}$ & 1.04 & $0.95-1.15$ & .3512 \\
\hline Aortic neck angle $>60$ degrees & 1.49 & $0.64-3.19$ & .3406 \\
\hline Shorter leg length, $\mathrm{mm}$ & 1.00 & 0.98-1.02 & .9146 \\
\hline Wider leg diameter, mm & 1.07 & $0.99-1.17$ & .1101 \\
\hline \multicolumn{4}{|l|}{ Treatment } \\
\hline ePTFE vs polyester & 0.61 & $0.31-1.22$ & .1602 \\
\hline Operation time, minutes & 1.00 & $0.99-1.00$ & .9136 \\
\hline Blood loss, $\mathrm{mL}$ & 1.00 & $0.99-1.00$ & .9702 \\
\hline Blood transfusion & 1.20 & $0.45-2.73$ & .6918 \\
\hline \multicolumn{4}{|l|}{ Artery of T2Es } \\
\hline Both IMA and LA vs IMA & 0.97 & $0.24-3.49$ & .9601 \\
\hline Both IMA and LA vs LA & 1.32 & $0.38-3.46$ & .6236 \\
\hline IMA vs LA & 1.36 & $0.49-3.26$ & .5244 \\
\hline
\end{tabular}

